\title{
The Image Information Of Mri Brain In Axial Diffusion Weighted Image (Dwi) With Variation B Value In Ischemic Stroke
}

\author{
Siti Masrochah ${ }^{1, *}$,Yeti Kartikasari ${ }^{2}$, Ayu Mahanani ${ }^{3}$ \\ ${ }^{1,2}$ Health Polytechnics of Semarang-Indonesia \\ ${ }^{3}$ Student of Radiology Departement of Semarang Health Polytecnic \\ 1masrochah@yahoo.co.id* \\ * corresponding author \\ Submission date: 10 Juli 2018, Receipt date: 10 Oktober 2019, Publication date: 1 Juli 2020
}

\begin{abstract}
The purpose of the research is to identify the differences between image information of MRI Brain in axial plane Diffusion Weighted Image (DWI) sequence and variation b value in case ischemic stroke, and to determine optimal $b$ value in examination MRI Brain in case Ischemic Stroke. This research was a quantitative research with experimental approach. This research was done in Panti Rapih Hospital, Yogyakarta and used 8 ischemic stroke patients with 3 variasion b value $\left(500 \mathrm{~s} / \mathrm{mm}^{2}, 1000 \mathrm{~s} / \mathrm{mm}^{2}\right.$, $1500 \mathrm{~s} / \mathrm{mm}^{2}$ ) and 3 radiologists as respondents. The data were analyzed using Friedman test. Result showed that there was difference between image information of MRI Brain in axial plane Diffusion Weighted Image (DWI) sequence and variation b value in case ischemic stroke with $p<0.05$ which means there is a difference between Basal Ganglia, Cerebellum, and the border of the infarction. Meanwhile, Cortex Cerebri, Thalamus and Pons obtained no difference in image information and the optimal $b$ value for MRI Brain examination of ischemic stroke $1500 \mathrm{~s} / \mathrm{mm} 2$. Based on the result there was a difference between image information of MRI Brain in axial plane Diffusion Weighted Image (DWI) sequence and variation b value in case ischemic stroke. Optimal value of variation b value for MRI Brain examination of ischemic stroke was $1500 \mathrm{~s} / \mathrm{mm} 2$.
\end{abstract}

Keywords: MRI Brain, Ischemic Stroke, $b$ value

\section{INTRODUCTION}

Stroke is a disease of the brain in the form of impaired neural function locally or globally, the appearance of sudden, progressive, and fast. Nerve function impairment in stroke is caused by non traumatic brain circulation disorder. Neurological disorders cause symptoms include: facial or limb paralysis, speech is not fluent, speech is not clear, maybe changes in consciousness, impaired vision, and others. The number of stroke patients in Indonesia in 2013 based on the diagnosis of health workers (Nakes) is estimated to be $1,236,825$ people $(7.0 \%)$, whereas based on diagnosis Nakes or symptoms are estimated as $2,137,941$ people $(12,1 \%)$ (Trihono, 2013).

According to the way, the occurrence of stroke consists of 2 types: namely ischemic stroke and hemorrhagic stroke. Ischemic stroke is a stroke that occurs due to blood flow to the brain that stops because of atherosclerosis (the buildup of cholesterol in the blood vessel wall) or blood clot that has pulverized a blood vessel to the brain, whereas hemorrhagic stroke occurs because there is direct bleeding to the brain caused 
by blood leak of intracerebral arterioles damaged by high blood pressure (Caplan, 2016).

To be able to diagnose in the case of stroke one of the modalities that can be used is Magnetic Resonance Imagin (MRI). MRI is a medical imaging technique that uses magnetic and radiofrequency fields to visualize body tissues, blood flow, and metabolic functions of the body. One type of MRI examination is Brain examination (Notosiswoyo, Suswati, 2004).

The MRI Brain examination protocol according to Westbrook (2014) is T2 Axial FSE, T1 Axial SE, Axial FLAIR, T2 Sagital / Coronal FSE, and additional Axial Diffusion Weighted Image (DWI) sequences. The MRI Brain axial plane is a "gold standard" because it can show the organ more clearly than the other pieces (Tan, et al, 2005). DWI has a high sensitivity in diagnosing acute infarction in brain (Pereira, et al, 2002). DWI utilizes molecular motion used to describe movement in extra cellular space due to random thermal movement called diffusion. This movement is limited by boundaries such as ligaments, membranes and macromolecules. DWI is used to assess diffusion in brain tissue and is well used to detect early stroke.

DWI is controlled by $b$ value. $b$ value determines the sensitivity of movement or diffusion of water in extracellular tissues by modifying the duration and amplitude of the diffusion gradient. The range of $\mathrm{b}$ values is $500 \mathrm{~s} / \mathrm{mm} 2$ to $1500 \mathrm{~s} / \mathrm{mm} 2$ (Westbrook, 2014).

The diffuse brain tissue is limited, for example, to the infarct will produce a signal with a bright intensity (hyperintens) compared to normal brain tissue because the gradient is given to affect the spins of the immobile hydrogen atom, while the spin of hydrogen atoms moving on the normal tissue is unaffected (Westbrook, 2014). The displacement of molecules that tissue across the network area per second is called Apparent Diffusion Coeficient (ADC). In diffusion regions limited to low ADC values, whereas in free diffusion regions have high ADC values. In diffusion imaging, normal tissue that exhibits high ADC has a lower signal intensity than abnormal tissue that has low ADC because the molecule inside is free to move, while diffusion becomes limited in the presence of pathology (Westbrook, et al, 2011). ADC is used to determine whether the signal from abnormality in DWI image caused due to diffusion area is limited, as in sub-acute to chronic infarction (Moritani, et al, 2005). According to Chen's research, L.P (2017) on b value of $1000 \mathrm{~s} / \mathrm{mm} 2$ in ischemic stroke has a mean range of $350 \mathrm{~mm} 2 / \mathrm{s}-530 \mathrm{~mm} 2 / \mathrm{s}$. Specifically the ADC value will decrease along with the increase of $b$ value.

The results of research Kim, et al (2004) mentioned that on the results of qualitative analysis of increasing $b$ value on MRI brain, image of lesion will be more striking with high $b$ value. Pereira research, et al (2002) suggested that the b value used is $1000 \mathrm{~s} /$ $\mathrm{mm} 2$ to $1500 \mathrm{~s} / \mathrm{mm} 2$.

Standard Operating Procedure (SOP) of Radiology Installation in Panti Rapih Hospital, which is used for MRI Brain Stroke examination uses T2FSE Sagital, T2 GRE Axial, Axial Flair, T2 Coronal, T1 FSE Axial, and DWI with b value $1000 \mathrm{~s} / \mathrm{mm} 2$. The researcher is interested in identifying the value of Diffusion Weighted Image (DWI) sequence which will produce MRI image with optimum image quality in stroke case. 


\section{RESEARCH METHODS}

The population in this study were all MRI Brain examination in Panti Rapih Hospital Yogyakarta. The sample determination used the formula of Lameshow method (Notoatmodjo, 2002) :

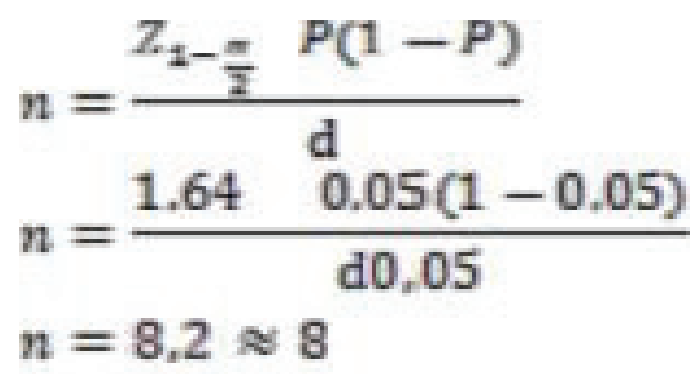

Where :

$\mathrm{N} \quad=$ sample size

$Z_{1-\frac{\alpha}{2}}=$ value at the degree of significance $(95 \%=1.64)$

$\mathrm{P}^{\overline{2}}=$ the proportion of a particular case to the population, if unknown proportion, is set $50 \%(0.05)$

$\mathrm{d}=$ degrees of deviation

The samples of this study were 8 patients who performed MRI Brain examination with ischemic stroke using DWI sequence with changes in b parameter values of $500 \mathrm{~s} /$ $\mathrm{mm} 2,1000 \mathrm{~s} / \mathrm{mm} 2,1500 \mathrm{~s} / \mathrm{mm} 2$. The procedure of making the image as Examination Procedure of MRI Brain Stroke case in Radiology Installation in Panti Rapih Hospital Yogyakarta are as follow:

a) Providing an explanation to the patient about the examination to be performed including the time of the examination.

b) Releasing all ferromagnetic object and if necessary replacing clothing with special clothing provided. Entering patient data to computer and selecting the sequence.

c) Preparing the head coil

d) The patient is positioned supine on the examination table with the head inside the head coil.

e) Arranging the head to interpupilari the parallel line with the examination table and make sure the head is straight.

f) The patient is positioned with longitudinal line on the MSP and horizontal line as high as the nassion.

g) Strap can be used as immobilization when needed.

h) After positioning the patient, closing the door tightly so there is no interference from outside.

i) Examination with MRI 1.5 T Brivo plane with controlled parameters TR, TE, Slice thickness, FOV

j) Creating a localized image and then creating a slice with sequences used in Panti Rapih Hospital T2 FSE Sagital; T2 GRE Axial, DWI b value of $1000 \mathrm{~s} / \mathrm{mm} 2$, Axial Flair, T2 Coronal, T1 FSE Axial, after the sequence is completed add DWI sequence with $\mathrm{b}$ value $\mathrm{b}$ value $500 \mathrm{~s} / \mathrm{mm} 2$ and $1500 \mathrm{~s} / \mathrm{mm} 2$. with the same procedure.

k) After the image is obtained the next step is to print on each image. 
Imaging Procedure was performed by three radiology specialists requested to examine the image of MRI Brain Stroke case that has been printed in the film with no description of either the identity of the patient or the parameters used and only given the image series code.

Assessment of radiology specialist for image information is done by giving a check mark (v) on the questionnaire provided in accordance with the instructions. The questionnaire contains an assessment of anatomical image information. Then the questionnaire results in the form of numbers to be processed using SPSS applications.

Data from questionnaires obtained from experimental results of three radiologist specialists on 8 patients with 3 variations of $b$ value of $500 \mathrm{~s} / \mathrm{mm} 2,1000 \mathrm{~s} / \mathrm{mm} 2$, $1500 \mathrm{~s} / \mathrm{mm} 2$. Data is processed and tested computerized using SPSS program. The results data of the reviewers in the questionnaire were conducted by Cohern's Kappa Test as the subjective consultant's consultant parameter. The value of Kappa according to Wadhiarso (2006) the value of relativity level among rater into four categories, among others:

1) Kappa $<0.4=$ bad

2) Kappa $0.4-0.60=$ enough

3) Kappa $0.61-0.75=$ good

4) Kappa $>0.75-1=$ very good

Data from questionnaire results by observer (radiology specialist) obtained from the result of comparison of three variations of $b$ value of sequence sequence Diffusion Weighted Image (DWI) on MRI Brain stroke case is ordinal. To determine the optimal $\mathrm{b}$ value to produce the Brain MRI image on the axial slice in the case of stroke, the researchers used the Friedman test.

In this analysis, the level of confidence (level of significance) with value $=0.05$. Ho is rejected if $\mathrm{p}$ value $<0.05$, which means there is a difference between image information MRI Brain piece axial sequence Diffusion

Weighted Image (DWI) and variation b value in case of Ischemic stroke.

a. Description of Sample Characteristics

\section{RESULTS AND DISCUSSION}

Table 1. Sample Description by Sex

\begin{tabular}{ccc}
\hline Sex & Amount & Percentage (\%) \\
\hline Male & 5 & $62.50 \%$ \\
Female & 3 & $37.50 \%$ \\
Total & 8 & $100 \%$ \\
\hline
\end{tabular}

Based on the table, it is known that this study used 8 ischemic stroke patients with males percentage of $62.5 \%$ and females $37.5 \%$

Table 2. Sample Description By Age

\begin{tabular}{ccc}
\hline Age & Amount & Percentage (\%) \\
\hline $40-50$ year & 3 & $37.50 \%$ \\
$51-60$ year & 5 & $62.50 \%$ \\
Total & 8 & $100 \%$ \\
\hline
\end{tabular}


Based on the table, this study used ischemic stroke patients as 8 people with age range 40-60 years

Table 3. Description of Sample Based on Weight

\begin{tabular}{ccc}
\hline Weight & Amount & Percentage (\%) \\
\hline $50-60 \mathrm{~kg}$ & 2 & $25 \%$ \\
$61-70 \mathrm{~kg}$ & 3 & $37.50 \%$ \\
$71-80 \mathrm{~kg}$ & 3 & $37.50 \%$ \\
Total & 8 & $100 \%$ \\
\hline
\end{tabular}

Based on the data, this study used 8 ischemic stroke patients with weight ranges from $50-60 \mathrm{~kg}$ by $25 \%, 61-70 \mathrm{~kg}$ by $37.5 \%$ and $71-80 \mathrm{~kg}$ by $37.5 \%$. Each result of the image of the patient produced 3 images on axial plane of DWI sequences with 3 variations of $b$ value value, one of the image results of the variation $b$ value to be judged by the respondent :

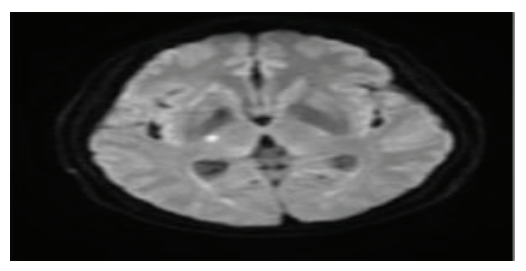

a

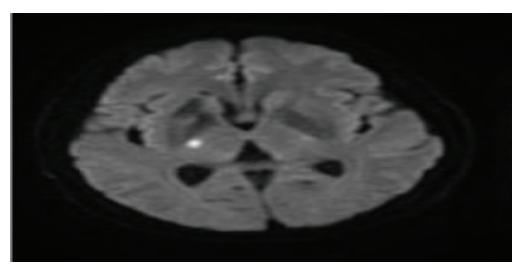

$\mathrm{b}$

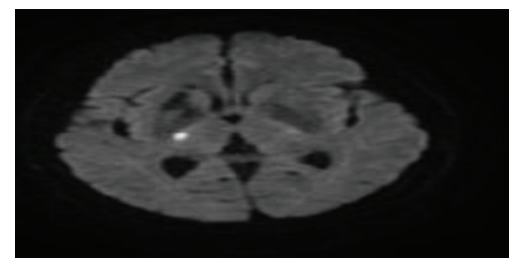

$\mathrm{c}$

Figure 1. MRI image Brain axial plane on the thalamus (a) $500 \mathrm{~s} / \mathrm{mm}^{2}$ (b) $1000 \mathrm{~s} / \mathrm{mm}^{2}$ (c) $1500 \mathrm{~s} / \mathrm{mm}^{2}$

From these results, it was, then, conducted an assessment by 3 respondents. The research respondents were radiology specialists who had the ability the expertise in the field of MRI more than 5 years. The respondent characteristics in this research are as follow:

Table 4. Respondent Characteristics

\begin{tabular}{ccc}
\hline Respondent & Working experience & Position \\
\hline 1 & 11 years & $\begin{array}{c}\text { Radiologist } \\
\text { Specialist }\end{array}$ \\
\hline 2 & 9 years & Radiologist \\
& & Specialist \\
\hline 3 & 8 years & Radiologist \\
& & Specialist \\
\hline
\end{tabular}

Respondents filled out the questionnaire in the form of checklist consisting of anatomical characteristics on the image result of each variation of value $b$ value. Six anatomical criteria in this study were Cortex Cerebri, Basal Ganglia, Thalamus, Pons, Cerebellum, Infarcts (limit). The respondent then analyzed the questionnaire by using scoring scores (score 1 = less clear, 2 = clear enough, 3 = clear). 

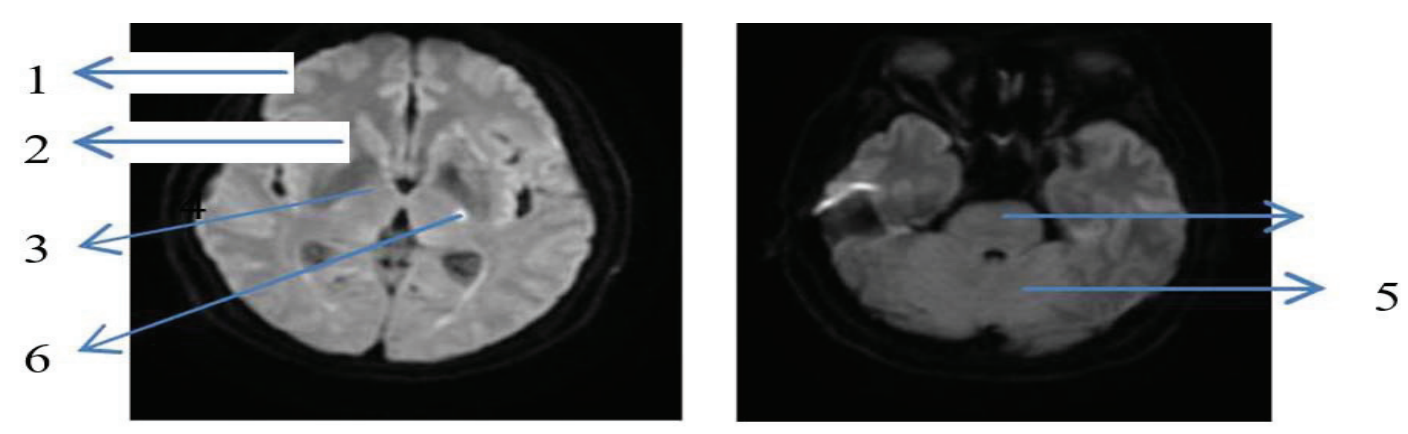

Figure 2. Anatomical image to be assessed Respondents

(1) Cortex Cerebri, (2) Basal Ganglia, (3) Thalamus, (4) Pons, (5) Cerebellum, (6) Infarction

b. The differences between Image of MRI Brain Information and variation of $b$ value of Sequence of Diffusion Weighted Image (DWI) in Ischemic Stroke patients.

Respondents Conformity Test Results

The result of the research was analyzed using statistic test namely SPSS 23 that is Cohen's Kappa test to identify the objectivity between respondents (respondent 1 with respondent 2 , respondent 1 with respondent 3 , and respondent 2 with respondent 3 ).

The results of questionnaires from three respondents were analyzed by using Cohen's Kappa test to determine the level of agreement of the objectivity of the three respondents to the study. Cohen's Kappa test tested on every variation. The statistical test results of Cohen's Kappa :

Table 5. Cohen's Kappa Test Respondents

\begin{tabular}{cccc}
\hline \multirow{2}{*}{ b value } & \multicolumn{3}{c}{ Level of objectivity } \\
\cline { 2 - 4 } & R1 and R2 & R1 and R3 & R2 andR3 \\
\hline $500 \mathrm{~s} / \mathrm{mm}^{2}$ & 0.762 & 0.813 & 0.677 \\
$1000 \mathrm{~s} / \mathrm{mm}^{2}$ & 0.659 & 0.744 & 0.719 \\
$1500 \mathrm{~s} / \mathrm{mm}^{2}$ & 0.447 & 0.556 & 0.551 \\
\hline
\end{tabular}

According to Wadhiarso (2006), the value of Kappa in relativity level among rater is divided into four categories :
1. Kappa $<0.4=$ poor
2. Kappa $0.4-0.60=$ moderate
3. Kappa $0.61-0.75=$ good
4. Kappa $>0.75-1=$ very good

Based on statistical test of Cohen's Kappa, there were three respondents in assessing the image of MRI Brain Axial pieces who had moderate until very good value. Therefore, it could be considered as one of the most experienced respondents in their field (11 years of service). Then after the Cohen's Kappa statistic test, the Friedman test was used to determine the difference of variation $b$ value of one of the respondents who have been tested Cohen's Kappa. 
Table 6. Recapitulation of Respondent Questionnaire Value 1 on Image Information with Variation b

\begin{tabular}{lccc} 
& \multicolumn{3}{c}{ Value } \\
& Organ & \multicolumn{3}{c}{ Variation b value } \\
\cline { 2 - 4 } & $\mathbf{5 0 0} \mathbf{~ s} \mathbf{m}^{\mathbf{2}}$ & $\mathbf{1 0 0 0} \mathbf{~} / \mathbf{m m}^{\mathbf{2}}$ & $\mathbf{1 5 0 0} \mathbf{~ s} / \mathbf{m m}^{\mathbf{2}}$ \\
\hline Cortex & 18 & 20 & 22 \\
Cerebri & & & 24 \\
Basal Ganglia & 16 & 17 & 21 \\
Thalamus & 19 & 20 & 24 \\
Pons & 21 & 22 & 23 \\
Cerebellum & 18 & 20 & 24 \\
Infark (batas) & 16 & 18 & \\
\hline
\end{tabular}

Based on the above table, it can be concluded that the increase in the value of $b$ value is followed by the increase in values on the 6 criteria of anatomy such as Cortex Cerebri, Basal Ganglia, Thalamus, Pons, Cerebellum, and Infarct (limits). Data from respondent 1 were tested by Friedman Statistical Test to investigate the difference between variation of $b$ value and image information of MRI Brain piece axial. The results of the Friedman test on each variation are as follows:

Table 7. Friedman Test Results for whole organs in each variation

\begin{tabular}{cccc}
\hline B value & Mean Rank & significance & Meaning \\
\hline $500 \mathrm{~s} / \mathrm{mm}^{2}$ & 1.67 & 0 & Different \\
$1000 \mathrm{~s} / \mathrm{mm}^{2}$ & 1.76 & 0 & Different \\
$1500 \mathrm{~s} / \mathrm{mm}^{2}$ & 2.57 & 0 & Different \\
\hline
\end{tabular}

From the results of Friedman test, for the whole organs on each variation of $b$ value was significance $=0.00(\mathrm{p}<0.05)$ which means there was a difference between each variation for the whole organ. Based on the mean rank result, the highest value was the value of $1500 \mathrm{~s} / \mathrm{mm} 2$ with mean rank 2.57, the second rank was the value of $1000 \mathrm{~s} / \mathrm{mm} 2$ with mean rank 1.76 and third rank was at $500 \mathrm{~s} / \mathrm{mm} 2$ with mean rank 1.67. Based on the mean rank value, based on Friedman test, the best outcome picture of the whole organ was value $b$ of $1500 \mathrm{~s} / \mathrm{mm} 2$ and the lowest result was on variation $\mathrm{b}$ value $500 \mathrm{~s} / \mathrm{mm} 2$. The Friedman test on the whole organs aimed to identify the difference variation of value $b$ value of image information on each organ of the axial pieces head. The results of Friedman's Test on each organ are as follow:

Table 8. Result of Friedman Test Significance Variation of b value on every organ of MRI Brain

\begin{tabular}{lccc}
\hline \multicolumn{1}{c}{ Organ } & Variation b value & P value & Meaning \\
\hline Cortex & $500 \mathrm{~s} / \mathrm{mm}^{2}$ & 0.156 & No Difference \\
Cerebri & $1000 \mathrm{~s} / \mathrm{mm}^{2}$ & & \\
& $1500 \mathrm{~s} / \mathrm{mm}^{2}$ & & No Difference \\
\hline Basal Ganglia & $500 \mathrm{~s} / \mathrm{mm}^{2}$ & 0.021 & \\
& $1000 \mathrm{~s} / \mathrm{mm}^{2}$ & & No Difference \\
& $1500 \mathrm{~s} / \mathrm{mm}^{2}$ & & \\
\hline Thalamus & $500 \mathrm{~s} / \mathrm{mm}^{2}$ & 0.093 & No Difference \\
& $1000 \mathrm{~s} / \mathrm{mm}^{2}$ & &
\end{tabular}




\begin{tabular}{|c|c|c|c|}
\hline & $\begin{array}{l}1000 \mathrm{~s} / \mathrm{mm}^{2} \\
1500 \mathrm{~s} / \mathrm{mm}^{2}\end{array}$ & & \\
\hline Cerebellum & $\begin{array}{l}500 \mathrm{~s} / \mathrm{mm}^{2} \\
1000 \mathrm{~s} / \mathrm{mm}^{2} \\
1500 \mathrm{~s} / \mathrm{mm}^{2}\end{array}$ & 0.002 & No Difference \\
\hline Infark & $500 \mathrm{~s} / \mathrm{mm}^{2}$ & 0.001 & No Difference \\
\hline
\end{tabular}

Based on the table, the results of significance from Friedman test found that in Cortex cerebri organ, Thalamus and Pons obtained no difference in MRI Brain image information, whereas in organ Basal Ganglia, there was a difference in MRI brain image between Cerebellum and edge of the infarct.

Table 9. Result of Mean Rank Test Friedman variation b value on every organ MRI Brain

\begin{tabular}{lcc}
\hline \multicolumn{1}{c}{ Organ } & Variation of p & Mean Rank value \\
\hline Cortex Cerebri & $500 \mathrm{~s} / \mathrm{mm}^{2}$ & 1.56 \\
& $1000 \mathrm{~s} / \mathrm{mm}^{2}$ & 2.13 \\
& $1500 \mathrm{~s} / \mathrm{mm}^{2}$ & 2.32 \\
\hline Basal Ganglia & $500 \mathrm{~s} / \mathrm{mm}^{2}$ & 1.56 \\
& $1000 \mathrm{~s} / \mathrm{mm}^{2}$ & 1.75 \\
& $1500 \mathrm{~s} / \mathrm{mm}^{2}$ & 2.69 \\
\hline Thalamus & $500 \mathrm{~s} / \mathrm{mm}^{2}$ & 1.5 \\
& $1000 \mathrm{~s} / \mathrm{mm}^{2}$ & 2.06 \\
& $1500 \mathrm{~s} / \mathrm{mm}^{2}$ & 2.44 \\
\hline Pons & $500 \mathrm{~s} / \mathrm{mm}^{2}$ & 1.56 \\
& $1000 \mathrm{~s} / \mathrm{mm}^{2}$ & 2.13 \\
& $1500 \mathrm{~s} / \mathrm{mm}^{2}$ & 2.31 \\
\hline Cerebellum & $500 \mathrm{~s} / \mathrm{mm}^{2}$ & 1.56 \\
& $1000 \mathrm{~s} / \mathrm{mm}^{2}$ & 1.56 \\
& $1500 \mathrm{~s} / \mathrm{mm}^{2}$ & 2.88 \\
\hline Infark (batas) & $500 \mathrm{~s} / \mathrm{mm}^{2}$ & 1.44 \\
& $1000 \mathrm{~s} / \mathrm{mm}^{2}$ & 1.63 \\
\hline
\end{tabular}

\section{The result of MRI Brain Image in Axial Sequence Diffusion Weighted Image (DWI) with Variation b Value On Ischemic Stroke Case}

Friedman test is to determine difference in each variable. In Friedman test of the whole organ on each variation of value of $b$ value is $p<0.05$ that Ha accepted means there is difference in each variation of value of $b$ value in whole organ. Then tested Friedman In each anatomical organ for Cortex Cerebri, Thalamus and Pons $p>0.05$ value is Ho accepted means there is no difference in anatomical image information on $\mathrm{b}$ value variation, whereas for organ Basal Ganglia, Cerebellum, Infarct (limit) $p$ value $<0.05$ ie Ha accepted means there is a difference in anatomical image information on the variation of $b$ value. The difference is due to the selection of $b$ values that affect the intensity of the diffusion signal. According to Pereira (2002), the selection of $b$ value parameters will affect signal intensity and diffusion sensitivity. 
The optimal value of $b$ value to show Image Information of MRI Brain Axial plane Sequence Diffusion Weighted Image (DWI) with Variation b Value On Ischemic Stroke Case.

Based on the results of Friedman test, the highest mean rank result is the value of $1500 \mathrm{~s} / \mathrm{mm} 2$ with mean rank 2.57, the second rank is the value of $1000 \mathrm{~s} / \mathrm{mm} 2$ with mean rank 1.76 and third rank is the value of $500 \mathrm{~s} / \mathrm{mm} 2$ with mean rank 1.67. whereas, the best result outcome based on Friedman test is b value $1500 \mathrm{~s} / \mathrm{mm} 2$ and the lowest result is on variation $\mathrm{b}$ value $500 \mathrm{~s} / \mathrm{mm} 2$.

The differences Intensity of diffusion signal on MRI image Brain in axial plane of DWI sequence are caused by the influence of selection of $b$ value in intensity of diffusion signal. This is in accordance with the theory that the selection of $b$ value will affect the intensity of the diffusion signal and the diffusion sensitivity (Pereira, et al, 2002). Diffusion sensitivity is the ability to distinguish diffusion abnormalities in brain tissue (ex in brain tissue infarcted). If the intensity of the diffusion signal gets stronger, the image results in the diffusion of normal brain tissue will appear darker and the limited diffusion brain tissue will appear bright on the image. The higher the value, the stronger the intensity of the diffusion signal and the diffusion sensitivity will increase. If the $b$ value is higher, the image result in normal brain tissue will be darker (Westbrook, 2014).

From the result of research, it is concluded that the best diffusion signal intensity is at $b$ value $1500 \mathrm{~s} / \mathrm{mm} 2$ and the lowest intensity of diffusion signal is at $b$ value $500 \mathrm{~s} /$ $\mathrm{mm} 2$. Because of the higher $\mathrm{b}$ value, the diffusion gradient gets stronger so that the diffusion signal intensity will get better and the diffusion sensitivity also increases and the other way. To obtain good image information on the organ of Basal Ganglia, Cerebellum, the border of infarct can use $b$ value $1500 \mathrm{~s} / \mathrm{mm} 2$, and if there are abnormalities in Cortex Cerebri, Thalamus, and Pons organ can use variations of $500 \mathrm{~s} /$ $\mathrm{mm} 2,1000 \mathrm{~s} / \mathrm{mm} 2,1500 \mathrm{~s} / \mathrm{mm} 2$. In Cortex Cerebri, the mean rank for the variation of $1500 \mathrm{~s} / \mathrm{mm} 2$ is 2.31 , the second spread on $b$ value of $1000 \mathrm{~s} / \mathrm{mm} 2$ is 2.13 , while for the variation of $500 \mathrm{~s} / \mathrm{mm} 2$ has the mean value of 1.56 . The significance of $b$ value variation on each organ of Cortex Cerebrii is 0.156 which means there is no difference of each variation of $b$ value on organ of Cortex Cerebrii, because in cortex cerebri consist of gray matter structure so that on variation $b$ value $500 \mathrm{~s} / \mathrm{mm} 2,1000 \mathrm{~s} / \mathrm{mm} 2$, and $1500 \mathrm{~s} / \mathrm{mm} 2$ will produce the same image (Delano, et al, 2000).

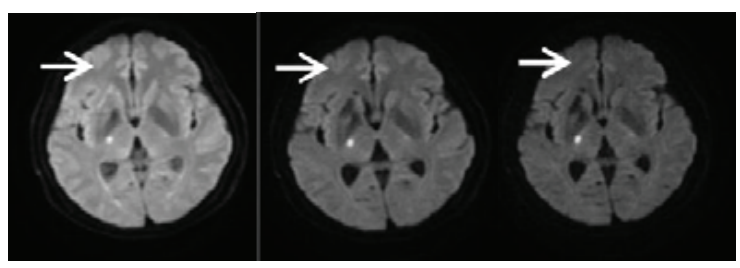

a

$\mathrm{b}$

c

Figure 3. MRI image Brain axial plane on cortex cerebri, (a) $500 \mathrm{~s} / \mathrm{mm}^{2}$ (b) $1000 \mathrm{~s} / \mathrm{mm}^{2}$ (c) 1500 $\mathrm{s} / \mathrm{mm}^{2}$

At Basal Ganglia the Significance is 0.021 which means there is a difference of each variation of $b$ value on the organ of Basal Ganglia. The higher the selection of $b$ 
values the contrast will increase and the resulting hypointens image (Delano, et al, 2000)

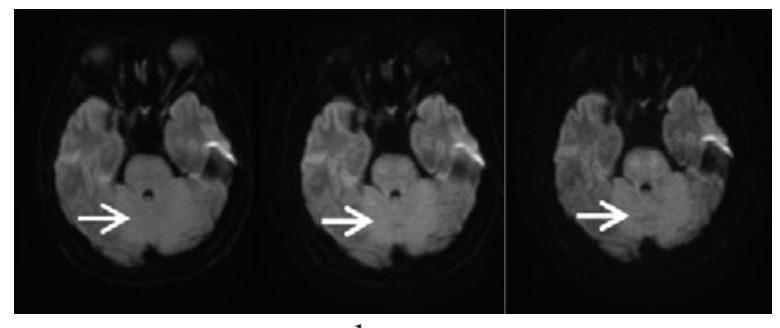

a

$\mathrm{c}$

Figure 4. MRI image Brain axial plane the basal ganglia (a) $500 \mathrm{~s} / \mathrm{mm}^{2}$ (b) $1000 \mathrm{~s} / \mathrm{mm}^{2}$ (c) $1500 \mathrm{~s} / \mathrm{mm}^{2}$

In Thalamus the Significance is 0.093 which means there is no difference of each variation of $b$ value on the thalamus organ, because in the thalamus consists of gray matter structure and has many thalamic nucleus so that the selection of b value of $500 \mathrm{~s}$ / mm2, $1000 \mathrm{~s} / \mathrm{mm} 2$, and $1500 \mathrm{~s} / \mathrm{mm} 2$ will produce the same image (Joshi, 2016).

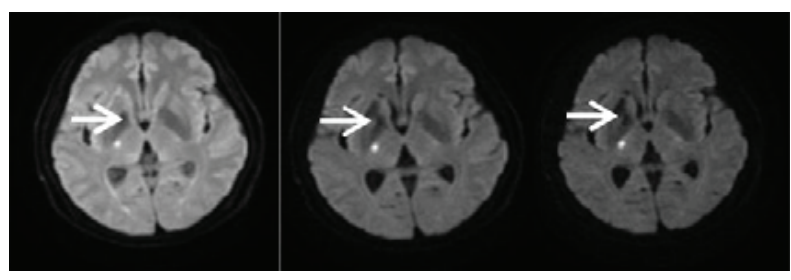

a

b

$\mathrm{c}$

Figure 5. MRI image Brain axial plane on the cerebellum (a) $500 \mathrm{~s} / \mathrm{mm}^{2}$ (b) $1000 \mathrm{~s} / \mathrm{mm}^{2}$ (c) $1500 \mathrm{~s} / \mathrm{mm}^{2}$

In Infark (limit) the Significance is 0.001 which means there is a difference of each variation of $b$ value in infarct organs (limit). If the selection of $b$ values is igh, the contrast will increase and the resulting image of hypergens (Westbrook, 2014)

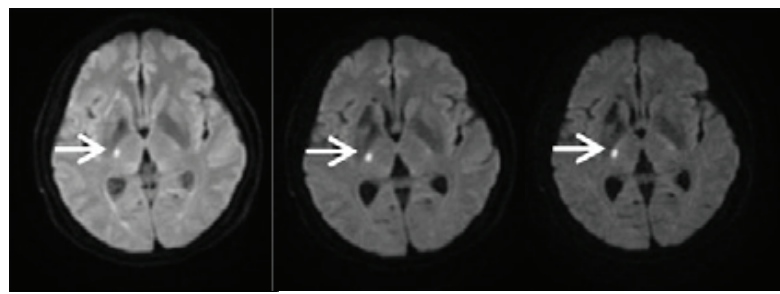

a

b C

Figure 6. MRI image Brain axial plane on the thalamus (a) $500 \mathrm{~s} / \mathrm{mm}^{2}$ (b) $1000 \mathrm{~s} / \mathrm{mm}^{2}$ (c) $1500 \mathrm{~s} / \mathrm{mm}^{2}$

In Pons the Significance is 0.115 which means there is no difference in each variation of $b$ value in pons organ, because the pons organ contains an important nervous system such as myelin axon in large quantities that serves to channel the impulse to the brain so that the selection of $b$ value $500 \mathrm{~s} / \mathrm{mm} 2,1000 \mathrm{~s} / \mathrm{mm} 2$, and $1500 \mathrm{~s} / \mathrm{mm} 2$ will produce the same image (Johansen, Timooty, 2009). 


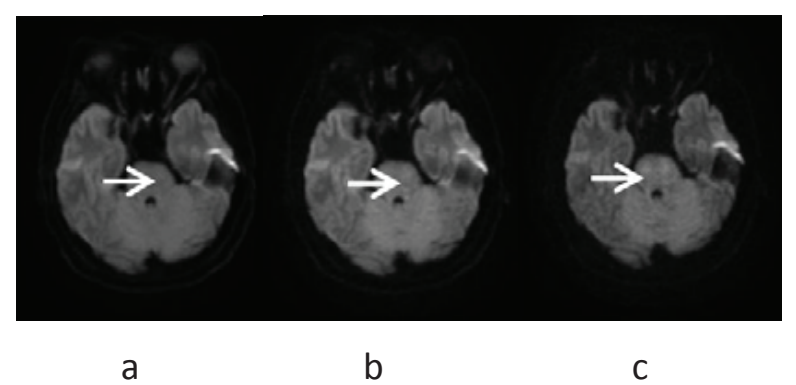

Figure 7. MRI image Brain axial plane on the pons (a) $500 \mathrm{~s} / \mathrm{mm}^{2}$ (b) $1000 \mathrm{~s} / \mathrm{mm}^{2}$ (c) $1500 \mathrm{~s} / \mathrm{mm}^{2}$

In Cerebellum the Significance is 0.002 which means there is a difference of each variation of $b$ value in cerebellum organ. The higher the selection of $b$ values the contrast will

\section{CONCLUSION}

Based on the results of the study and discussion, it can be concluded that there is a difference of MRI brain image information of Axial sequence of Diffusion Weighted Image (DWI) with variation of $b$ value in case of ischemic stroke with variation $b$ value of $500 \mathrm{~s} / \mathrm{mm} 2,1000 \mathrm{~s} / \mathrm{mm} 2,1500 \mathrm{~s} / \mathrm{mm} 2$ with value significance $=0.00(\mathrm{p}<0.05)$ indicating there is a difference of image information in the organ of Basal Ganglia, Cerebellum, and the boundary of infarction. Meanwhile, there is no difference in image information in cerebral cortex, thalamus and Pons organ. The optimal value of $b$ value on MRI examination of ischemic stroke cases mainly shows the limit of infarct can be used $\mathrm{b}$ value $1500 \mathrm{~s} / \mathrm{mm} 2$ with the mean value of 2.57 .

\section{REFERENCES}

Caplan, L.R, 2016, Stroke A Clinical Approach, Fifth Edition, University Printing House, USA.

Delano, M.C, Cooper, T.G, Siebert, J.E, Potchen, M.J, Kuppusamy, K, 2000," High-b-value Diffusion-weighted MR Imaging of Adult Brain: Image Contrast and Apparent Diffusion Coefficient Map Features" 